\title{
Adoção de jogo de negócios sob a perspectiva de modelo de excelência da gestão em curso de MBA: análise das avaliações multicritério por pares
}

\author{
KaIZô IWAKAMI BELTRÃo ${ }^{1}$ \\ LUIZ CeSAR BARÇANTE ${ }^{2}$
}

\author{
${ }^{1}$ Fundação Getulio Vargas (FGV EBAPE) / Escola Brasileira de AdMinistração Pública e de EMpresas, Rio de JANEIRO - RJ, BRASIL
}

2 BARSANTI BUSINESS \& GAMIFICATION, RIO DE JANEIRO - RJ, BRASIL

\begin{abstract}
Resumo
Este artigo descreve um jogo de negócios aplicado em cursos do tipo Master of Business Administration (MBA) como uma das últimas disciplinas do currículo e analisa os resultados de sua implementação em 47 turmas, envolvendo 1.410 alunos. O jogo de negócios tem por objetivo integrar as habilidades e competências desenvolvidas ao longo do curso e considera um sistema de avaliação com 39 quesitos baseado em um modelo de excelência que abrange todos os aspectos importantes no processo de gestão. Somente 6 quesitos de avaliação são financeiros e os outros 33 são avaliados pelos próprios alunos, em uma avaliação por pares, e dizem respeito à relação cliente-fornecedor e à gestão de cada empresa. Uma redução de dimensionalidade foi obtida por meio de uma análise fatorial, resultando em 14 fatores. Dentre esses fatores, é possível identificar quais são relevantes para o sucesso no jogo? Esta questão é respondida averiguando por meio de 2 métodos estatísticos distintos (significância dos parâmetros de um modelo logito e teste $t$ para diferença de médias) quais são esses fatores. Ajustou-se um modelo linear generalizado com uma função de ligação logito e uma distribuição Bernouilli, confirmando que a maioria dos fatores com diferenças estatisticamente significativas das médias de vencedores e demais participantes também foram estatisticamente significativas no modelo. A avaliação dos alunos participantes confirmou que o jogo de negócios foi bem recebido: levantou o moral dos alunos; despertou o interesse pelo assunto; fomentou o empreendedorismo; diminuiu o absenteísmo; aumentou a participação em sala, a consciência do trabalho em grupo e o planejamento; e criou um ambiente favorável às discussões sobre ética nos negócios.
\end{abstract}

Palavras-chave: Master of Business Administration. Jogos de negócios. Modelo de excelência da gestão. Análise fatorial. Modelo logito.

\section{Adoption of a business game under the perspective of an excellence model in an MBA course: peer analysis of multicriteria evaluation}

\begin{abstract}
This article describes a business game applied in one of the last courses of an MBA. The database analyzed consists of outcomes from 47 classes and 1410 students. The aim of the game is to integrate skills and abilities acquired during the program. It considerers an evaluation system with 39 items based on an Excellence Model which covers important aspects of the management process. Six of the evaluation items are financial goals, and the remaining 33 go through peer evaluation. These items deal with consumer-supplier aspects as well as management issues. A reduction of dimensionality was attained through factor analysis, yielding 14 factors. The research question is: Is it possible to identify relevant factors for winning the game? Two distinct tests were applied to answer the question: significance of a logit model parameters and t-test for equality of means. A generalized linear model using a logit link function and a Bernouilli distribution were fit to the data, confirming that most factors with statistically significant differences in the mean between winners and other participants were also significant in the model. Participants feedback confirmed that the game was well received by the students: it boosted students' morale, increased interest in the subject, fostered entrepreneurship and less absenteeism, increased class participation, awareness of teamwork and planning, and created an environment which favored discussion on business ethics.
\end{abstract}

Keywords: MBA. Business game. Business excellence model. Factor analysis. Logit model.

\section{Adopción de juego de negocios desde la perspectiva del modelo de excelencia en gestión en cursos de MBA:} Análisis de evaluaciones multicriterio por pares

\section{Resumen}

Este artículo describe un juego de negocios aplicado en los cursos de MBA, como una de las últimas asignaturas del programa y analiza los resultados de su implantación en 47 clases y 1.410 alumnos. El juego tiene como objetivo integrar las habilidades y competencias desarrolladas a lo largo del curso y considera un sistema de evaluación con 39 cuestiones basado en un modelo de excelencia que abarca todos los aspectos importantes del proceso de gestión. Sólo seis cuestiones de la evaluación son financieras y las otras 33 son evaluadas por los propios alumnos, en una evaluación por pares, y se refieren a la relación cliente-proveedor y a la gestión de cada empresa. Mediante un análisis factorial se obtuvo una reducción de dimensionalidad que resultó en 14 factores. Para responder la pregunta ¿entre esos factores, es posible identificar cuáles son relevantes para el éxito en el juego? se aplicaron dos tests (significancia de los parámetros de un modelo logit y prueba t para igualdad de medias). Se ajustó un modelo lineal generalizado con una función de enlace logit y una distribución Bernouilli, que confirman que la mayoría de los factores con diferencias estadísticamente significativas de los promedios de ganadores y demás participantes, también fueron estadísticamente significativas en el modelo. Los comentarios de los alumnos participantes confirmaron que el Juego fue bien recibido: levantó la moral de los alumnos, despertó el interés por el tema, fomentó el espíritu emprendedor, disminuyó el absentismo, aumentó la participación en el aula, la conciencia del trabajo en grupo y la planificación, y creó un ambiente favorable a las discusiones de grupo sobre ética en los negocios.

Palabras clave: MBA. Juegos de negocios. Modelo de excelencia de la gestión. Análisis factorial. Modelo logit. 


\section{INTRODUÇÃO}

Tem-se assistido a uma revolução no processo de criação de valor desde o final do século XX que pode ser atribuída, em parte, à confluência da globalização e dos avanços tecnológicos a partir da transição de uma economia industrial para uma economia baseada na informação. Esse contexto envolve grande complexidade, instabilidade e incerteza. Dessa forma, as mudanças organizacionais passam a ser encaradas como um dos principais meios para estruturar e explorar o novo mundo dos negócios. Essa exploração das novas formas organizacionais demandam que as instituições de Ensino Superior (IES) "joguem" estrategicamente com suas capacidades de ensino, pesquisa e extensão, de modo a aproximar o mundo acadêmico do mundo empresarial.

Nesse contexto, os cursos de pós-graduação lato sensu denominados Master of Business Administration (MBA) têm experimentado, principalmente nas últimas duas décadas, uma progressiva e acentuada expansão, reforçando sua importância social e econômica como instrumento de atualização, qualificação e capacitação de profissionais para o mercado de trabalho. Esses cursos têm um importante papel no crescimento econômico do país, envolvendo aspectos financeiros e estimulando novos investimentos, quer seja em infraestrutura, construção de ambientes apropriados, sonorização desses ambientes, aquisição de equipamentos de multimídia, pagamento dos professores e funcionários, viagens e estadia de professores, entre outros. São, em si, poderosos geradores de empregos e aglutinadores de atividades de serviço, comércio e indústria. Essa nova concepção parte da ideia de que seus alunos, em sua maioria profissionais atuantes no mercado, não são simplesmente receptores de informação - o pressuposto básico em aulas tradicionais -, mas ativos intangíveis, devendo ser tratados como tais.

A relevante função que esses cursos vêm desempenhando suscita a necessidade da utilização de novas técnicas de ensino que visem, por um lado, a fazer uma releitura do trabalho do professor, que passa a ser visto como um facilitador do aprendizado e, por outro, o total envolvimento do aluno com o processo de ensino-aprendizagem, o que é denominado aprendizagem vivencial (KOLB, 1984).

Os estudos relacionados à aprendizagem vivencial (WOLFE e KEYS, 1997) estabeleceram uma ligação entre ela e as simulações empresariais e os jogos de negócios, internacionalmente conhecidos como simulation \& gaming (S\&G).

O uso de $S \& G$ tem crescido nos últimos anos no Brasil (BARÇANTE, PITHON e BROCHADO, 2010) tanto no ambiente acadêmico como no empresarial. A previsão de Rosas e Sauaia (2006) tem se concretizado nos dias atuais nos cursos de pós-graduação: as mais importantes escolas de negócios do Brasil têm adotado disciplinas como jogos de negócios, jogos de empresas, simulações empresariais ou business games em seus programas, jogos estes que, via de regra, são bem avaliados pelos alunos.

Essas disciplinas proveem um ambiente de sala de aula mais próximo do ambiente de um mercado competitivo e constituem técnicas de ensino que estimulam a criatividade, promovem o exercício da comunicação, permitem o intercâmbio de experiências, estimulam a vivência de novos papéis e a tomada de decisão em ambiente de risco (VERSIANI e FACHIN, 2007) e têm experimentado uma grande expansão em nível mundial, inclusive no Brasil, nos últimos 40 anos (BRAGGE, THAVIKULWAT e TÖYLI, 2011; FARIA, HUTCHINSON e WELLINGTON, 2009). O número de artigos publicados somente em um periódico internacional, Simulation \& Gaming, entre 1970 (v. 1, n. 1) e 2017 (v. 48, n. 5) foi 2.360 (SIMULATION \& GAMING: AN INTERDISCIPLINARY JOURNAL, 1970-2017).

No que diz respeito às publicações em congressos brasileiros, o número é bem mais modesto. A Tabela 1 apresenta o número de artigos sobre jogos de negócios apresentados em 6 séries anuais de eventos, 3 em Administração e 3 em Engenharia. Esses eventos foram escolhidos por ser os fóruns mais frequentes para publicações de pesquisadores do tema. As informações foram colhidas nos anais on-line do(s): Congresso Brasileiro de Engenharia (COBENGE, 2017), de 1999 a 2016; Encontro Nacional de Engenharia de Produção (ENEGEP, 2017), de 1994 a 2016; Simpósio de Engenharia de Produção (SIMPEP, 2017), de 2000 a 2016; Encontro da Associação Nacional de Pós-Graduação e Pesquisa em Administração (ENANPAD, 2017), de 1990 a 2017; Encontro da Associação Nacional dos Cursos de Graduação em Administração (ENANGRAD, 2017), de 2004 a 2016; e Seminários em Administração (SEMEAD, 2017), de 1998 a 2016. 
Tabela 1

Artigos sobre jogos de negócios publicados em congressos brasileiros

\begin{tabular}{l|c|c|c|c|c|c|c}
\hline & $\begin{array}{c}\text { ENEGEP } \\
1994-2016\end{array}$ & $\begin{array}{c}\text { SIMPEP } \\
2000-2016\end{array}$ & $\begin{array}{c}\text { COBENGE } \\
1999-2016\end{array}$ & $\begin{array}{c}\text { ENANPAD } \\
1990-2017\end{array}$ & $\begin{array}{c}\text { ENANGRAD } \\
2004-2016\end{array}$ & $\begin{array}{c}\text { SEMEAD } \\
1998-2016\end{array}$ & TOTAL \\
\hline Até 2000 & 18 & 1 & 5 & 8 & - & 1 & 33 \\
\hline $2001-2010$ & 52 & 22 & 15 & 52 & 8 & 43 & 191 \\
\hline $2011-2014$ & 48 & 15 & 15 & 10 & - & 26 & 114 \\
\hline $2015-2017$ & 7 & 3 & 4 & 3 & 4 & 7 & 28 \\
\hline TOTAL & 125 & 41 & 38 & 73 & 12 & 77 & 366 \\
\hline
\end{tabular}

Fonte: Elaborada pelos autores.

Este artigo utiliza os resultados de aplicações de um jogo de negócios em 47 turmas de MBA, com um total de 1.410 alunos alocados em 402 empresas, e averigua por meio de 2 métodos estatísticos distintos (significância dos parâmetros de um modelo logito e teste $t$ para diferença de médias), o que é relevante para o sucesso das empresas no jogo. A avaliação das empresas no jogo é baseada no que preconizam os modelos de excelência em gestão.

\section{Jogos empresariais}

A importância de uma simulação empresarial é assunto permanente no meio científico e vem sendo debatida exaustivamente, de forma não unívoca (GOSEN e WASHBUSH, 2004; GROSSLER, 2004; FARIA, 2001; MALIK e HOWARD, 1996). Na discussão sobre a validade do uso de jogos de negócios, há quase uma unanimidade no que diz respeito a um jogo de negócios ser fortemente dependente da qualidade do modelo utilizado e de sua implementação. Segundo Stainton, Johnson e Borodzicz (2010) existem 3 conjuntos de sugestões baseadas na literatura disponível e na experiência de criadores de jogos de negócios que podem ser adotadas, a fim de aprimorar o jogo. Essas sugestões dizem respeito a características relacionadas ao ambiente, ao conteúdo e à implementação do jogo em si.

O ambiente do jogo (ELGOOD, 1993; NORRIS, 1986; ALESSI, 1988) deve:

1. Ter verossimilhança, ou seja, proporcionar um ambiente mais próximo do mundo real dos negócios;

2. Ter uma complexidade e flexibilidade às mudanças, sem que se torne algo confuso; e

3. Ser competitivo e estratégico.

O conteúdo do jogo (KNOWLES, 1980) deve:

1. Ser abrangente e relevante o suficiente para tornar o exercício estimulante e os participantes motivados a se envolver;

2. Ser versátil e tratado com adequada profundidade, para poder atingir vários objetivos de aprendizagem; e

3. Propiciar o desenvolvimento do aprendizado dos participantes.

As jogadas (FARIA, 2001; BIGGS, 1999; GENTRY, 1990; KOLB, 1984) devem:

1. Mostrar que as decisões dos participantes impactam o desempenho da equipe;

2. Mostrar que o desempenho da equipe está relacionado com seu resultado no jogo;

3. Trabalhar os processos cognitivos por meio da teoria de gestão participativa;

4. Mostrar que o processo de aprendizagem pode ser comportamental por meio do learning by doing;

5. Permitir a cooperação e a parceria, tornando o exercício mais agradável e gratificante;

6. Ser vivenciais, para permitir a aprendizagem por meio da aplicação da teoria na prática;

7. Ser dinâmicas e permitir que os problemas que surjam sejam resolvidos prontamente pelos participantes; e

8. Integrar conhecimentos já adquiridos. 
Além das sugestões citadas, outras devem ser levadas em consideração. Segundo Hall (2004): a duração de cada jogada deve ser concebida de modo que haja tempo suficiente para a análise dos resultados, a tomada de decisão, os debates e a reflexão; o manual do jogo deve ser escrito de forma clara e objetiva, a fim de fornecer as informações necessárias aos participantes; os professores, vistos como facilitadores do aprendizado, precisam ser treinados e ter conhecimento técnico e empresarial suficiente para dar suporte e, principalmente, dar feedback aos participantes (GOSEN, 2004; HALL, 2004; WOLFE, 1997). Finalmente, o material de suporte (físico ou computacional) precisa passar por testes piloto de modo que sua aplicação seja confiável (OAKSHOTT, 1997).

\section{Modelos de excelência da gestão}

Há pelo menos 94 prêmios associados a modelos de excelência de negócios que são utilizados em 83 países (MOHAMMAD, MANN, GRIGG et al., 2011; LU, BETTS e CROOM, 2013) ao redor do mundo. O Modelo de Excelência da Gestão (MEG), criado em 1991 pela Fundação Nacional da Qualidade (FNQ) é um deles e serve como base para o prêmio da FNQ. O MEG vem sendo aprimorado, a fim de ajustar-se às mudanças do mercado e também pode ser usado como guia para tornar as empresas mais competitivas. À época de aplicação dos jogos, o MEG era composto por 13 fundamentos e oito critérios (FNQ, 2013) e foi o modelo usado como referência para a definição dos pesos e a elaboração dos quesitos de avaliação que são descritos neste artigo. Já foi utilizado com esse objetivo em cursos de graduação (BELTRÃO e BARÇANTE, 2015). Em 2016, o MEG passou por uma atualização (FNQ, 2016). A atualização inova ao formatar o modelo em 8 fundamentos, que substituem os antigos 8 critérios. Os fundamentos se desdobram em temas, os quais, por sua vez, são concretizados em processos. Para cada tema são sugeridas algumas ferramentas e metodologias. Vale ressaltar que a nova versão do MEG continua não sendo prescritiva quanto às ferramentas, à estrutura ou à forma de gerir o negócio. Fica a critério de cada organização encontrar a forma mais adequada de atender às necessidades e expectativas dos seus stakeholders (as diversas partes interessadas) e utilizar as informações advindas deles para formular seu planejamento estratégico, alinhando, integrando, compartilhando e direcionando toda a organização, para que ela atue com excelência na cadeia de valor e gere resultado para todas as partes interessadas (FNQ, 2013, 2016).

\section{Descrição do jogo enquanto disciplina}

Motta, Quintella e Melo (2012, p. 445) identificam nos cursos de graduação em Administração 2 abordagens distintas para a disciplina Jogos de Empresa: "a primeira trata a capacitação para a aplicação de jogos como ferramenta de ensino-aprendizagem; e a segunda trata a integração das diversas disciplinas específicas de gestão". Nos cursos de MBA, devido à experiência e aos saberes prévios dos alunos, esta disciplina segue, principalmente, a abordagem de integração de conhecimentos.

A partir de 1999, os cursos de MBA de uma IES com atuação em todo o território nacional vêm introduzindo a disciplina Jogos de Negócios em seus programas. Dentro desse universo será analisado um jogo de negócios (BARÇANTE e CORREA, 2001). $O$ JOGO (como é denominado neste artigo o jogo de negócios implementado) foi adaptado para cursos de MBA. Aqui, utilizamos os resultados do JOGO aplicado em 47 turmas, 1.410 alunos, em 21 cidades distribuídas em 9 estados.

O JOGO tem a duração de 16 horas-aula, divididas em 4 encontros distintos de 4 horas cada. Simula uma cadeia produtiva conhecida como do tipo pull, já que a cadeia produtiva é acionada pelo cliente (DAVIS, 2010). Essa cadeia é formada por 3 tipos de empresas (Lavras, Ourives e Joalherias), papel desempenhado por equipes de alunos atuando como fornecedores e clientes, e pelo Exportador, papel desempenhado pelo professor - que também desempenha o papel de Governo, garantindo o bom andamento do JOGO.

\section{A modelagem do JOGO}

A Figura 1 mostra a modelagem do JOGO, ressaltando que a cadeia fornecedor-cliente constituída por 3 setores (Lavras, Ourives e Joalherias) se inicia com a demanda definida pelo Exportador, que aciona as Joalherias. Estas, por sua vez, encomendam as joias aos Ourives que, para confeccioná-las, adquirem matéria-prima das Lavras. As relações de compra e venda são representadas pelas setas azuis. A performance das empresas é avaliada (representada pelas setas vermelhas) pelos stakeholders, de acordo com um formulário de avaliação (quesitos listados na primeira coluna da Tabela 2), cujos resultados determinam o vencedor do JOGO. 
Figura 1

\section{A modelagem do JOGO}

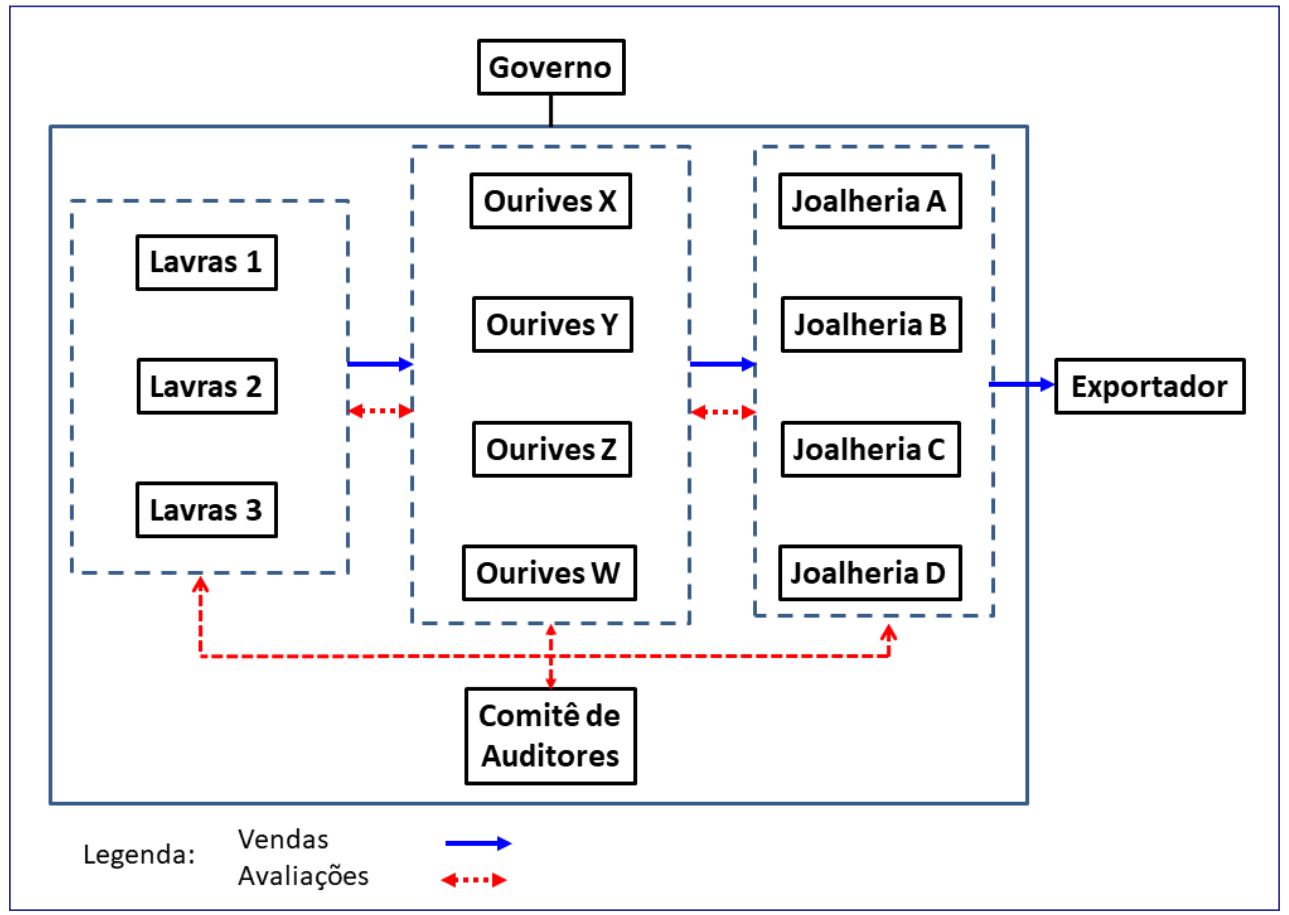

Fonte: Elaborada pelos autores.

As equipes são constituídas por:

- $\quad 2$ a 3 Lavras - recebem, e pagam (consignação ou outra forma), lotes de matéria-prima que será vendida como partes intercambiáveis para a produção de bens de consumo - joias. Vendem para os Ourives e os avaliam na relação cliente-fornecedor, em quesitos previamente definidos constantes do formulário de avaliação apresentado previamente aos participantes. Cada Lavra é formada por 2 alunos;

- $\quad 3$ a 4 Ourives - adquirem, por compra, das Lavras, partes intercambiáveis e produzem joias que são vendidas para as Joalherias. Avaliam ambas na relação cliente-fornecedor nos quesitos previamente definidos. As Joalherias são avaliadas como clientes e as Lavras como fornecedores. Para cada quesito, as empresas, recebem tipicamente notas de mais de um avaliador. A nota final alocada ao quesito na avaliação de uma empresa é a média das notas atribuídas pelos diferentes avaliadores. Cada Ourives é formado por, no mínimo, 3 alunos;

- $\quad 2$ a 4 Joalherias - adquirem joias dos Ourives, segundo demanda definida pelo Exportador. Avaliam os Ourives na relação cliente-fornecedor, nos quesitos previamente definidos. Cada Joalheria é formada por 2 alunos;

- Exportador - exercido pelo professor. Negocia lotes de joias (demanda do JOGO) com cada Joalheria, sem determinar cor ou formato das joias, apenas a quantidade de matéria-prima utilizada na confecção de cada joia. Em uma primeira instância, o Exportador determina os lotes de joias para as Joalherias. À medida que o JOGO se desenvolve, caso as Joalherias façam contrapropostas, o Exportador negocia a quantidade de joias e os preços caso a caso.

- Governo - também exercido pelo professor. Toma medidas de caráter geral, a fim de garantir que o JOGO privilegie a produção e a consequente gestão de cada negócio; e

- Comitê Auditor - formado por um grupo de alunos. Tem como função avaliar as empresas do JOGO como stakeholders, em quesitos específicos, representando outras partes interessadas (p. ex., órgãos do governo e segmentos da sociedade), e auxiliar o professor no feedback. 


\section{O lúdico}

Utilizam-se os "Pinos Mágicos" da Elka como matéria-prima a ser manuseada no JOGO. Estes são produzidos em 5 cores e 4 formatos. A escolha desse material se deve ao fato de ser um produto nacional de preço acessível e disponível no mercado.

As cores são: branca, amarela, vermelha, verde e azul. No jogo, representam metais preciosos e gemas, respectivamente, platina, ouro, rubelita, turmalina e água-marinha. Os pinos também são classificados quanto ao formato: pinos de 4 furos, pinos de 3 furos, pinos de 1 furo e meia-roda. Vale ressaltar que não são produzidos pinos com formato de meia-roda na cor verde. A Figura 2 apresenta uma joia formada por pinos de várias cores e formatos.

Figura 2

\section{Joia com diversos formatos e cores de pinos mágicos}

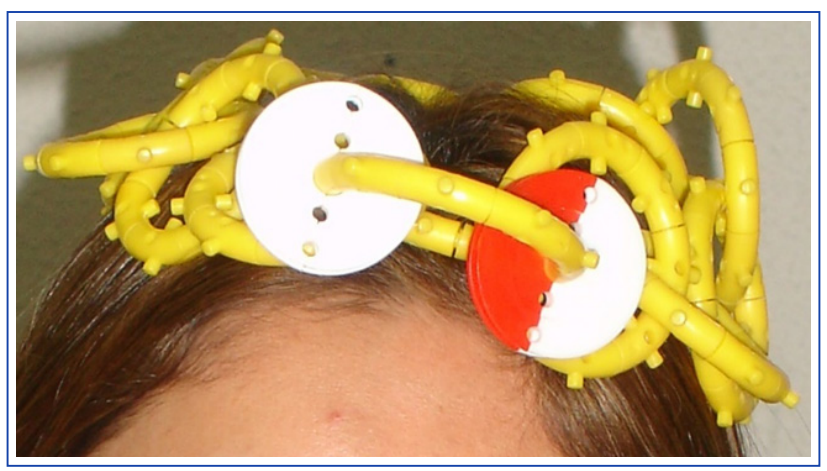

Fonte: Acervo pessoal dos autores.

Além de vender, comprar e manusear os pinos, fabricando joias, as empresas têm que gerenciar seu negócio como um todo, pagando a folha salarial, impostos e taxas, gerenciando os custos de armazenagem, custos variáveis, podendo investir em ações das outras empresas e determinando o pró-labore da diretoria, entre outros. Todas essas informações estão contidas no Manual do JOGO, distribuído aos alunos no primeiro dia de aula.

\section{Os quatro encontros do JOGO}

Como se trata de cursos de MBA (pós-graduação lato sensu com pelo menos 360 horas), a hipótese básica é que os alunos já detêm o conhecimento teórico, além de habilidades e competências necessárias para uma boa consecução do JOGO, seja por causa das disciplinas anteriores já cursadas, seja pelo conhecimento adquirido na graduação, nos treinamentos administrados pelas empresas ou nas atividades profissionais. Assim, no primeiro encontro é distribuído o manual, são apresentadas as regras do JOGO (inclusive o formulário que será utilizado na avaliação das empresas), formadas as equipes e instaladas as planilhas para coleta de dados nos computadores dos alunos. O segundo encontro é um grande ensaio geral, onde todas as atividades de compra, produção, vendas e avaliação são exercidas pelos alunos e pelo professor, simultaneamente. Nesse encontro os alunos se familiarizam com sua equipe, com os instrumentos (pinos e planilhas) e com as decisões e ações que precisam tomar para o desenvolvimento da cadeia produtiva. Os resultados dessa rodada não são considerados. No terceiro encontro ocorre a jogada propriamente dita, na qual os desempenhos das equipes também são avaliados, mas dessa vez para definir a classificação final e o vencedor. Essas avaliações são o objeto da análise que será feita a seguir. No quarto e último encontro ocorre a devolutiva, dirigida pelo professor. Nesse encontro, os alunos são distribuídos em grupos (não coincidentes com as equipes) e são instados a responder algumas questões com respostas individuais e coletivas, versando sobre seu desempenho e o da sua equipe. As respostas são utilizadas nesse processo, que também inclui o resultado final do JOGO.

\section{Estrutura dos dados (formulário)}

Como já comentado, os pesos e os quesitos do formulário de avaliação do JOGO foram baseados nos critérios de excelência do MEG (FNQ, 2013). Os 8 critérios de excelência eram na época: Liderança; Estratégia e Planos; Clientes; Sociedade; Informações e Conhecimento; Pessoas; Processos; e Resultados. No processo avaliativo do prêmio, esses 8 critérios eram subdivididos em 23 quesitos de avaliação (todos com alguns desdobramentos internos), sendo 17 relativos 
a processos gerenciais e 6 a resultados organizacionais. No formulário de avaliação do JOGO (os quesitos estão listados na primeira coluna da Tabela 2, onde o primeiro dígito se refere a 1 dos 8 critérios e o segundo ao seu desdobramento). Alguns critérios do MEG são avaliados com mais de um quesito, totalizando 39: 33 relativos a processos gerenciais e 6 a resultados econômico-financeiros. Apesar da nova nomenclatura, o MEG continua se baseando nos mesmos "valores e princípios internalizados nas organizações de classe mundial", e todos os quesitos do questionário são consistentes e contemplados pela nova versão.

Cada equipe recebe uma nota de 1 a 5 em cada um dos 33 quesitos relativos a processos gerenciais. Nos 6 quesitos econômicofinanceiros o valor da nota é dado pela ordenação dos resultados dentro de cada setor, exceto no quesito 8.2 Rentabilidade - se for negativa recebe nota zero (Tabela 2). Os quesitos têm pesos diferentes, consistentes com a pontuação do MEG (ver Tabela 2 para os pesos). A equipe com a maior média ponderada é a vencedora do JOGO.

Para controlar uma possível subjetividade dos avaliadores, particularmente do Comitê de Auditores (CA), as notas atribuídas pelo CA a cada quesito foram padronizadas pela mediana de cada quesito na turma.

\section{Análise}

Nesta seção são apresentados os resultados de uma análise fatorial e, para exemplificar, a distribuição dos valores obtidos para os dois primeiros fatores. Em seguida, um modelo linear generalizado é ajustado aos dados, utilizando os fatores identificados para explicar a probabilidade de sucesso no JOGO.

\section{Análise fatorial}

Foi aplicada uma análise fatorial aos 39 quesitos. Foram extraídos 14 fatores que explicam $72 \%$ da variância dos dados. A informação da carga fatorial associada a essa decomposição se encontra na Tabela 2. O Gráfico 1 apresenta as cargas fatoriais dos quesitos como função dos 2 primeiros fatores. Os quesitos que serviram como referências para nomear os fatores são evidenciados por elipses vermelhas. Para o Fator 1 (Foco no cliente), os quesitos foram: 2.1 - A empresa realiza pesquisas de satisfação de clientes; 2.2 - São tomadas medidas em cima das pesquisas de satisfação e das reclamações dos clientes; 3.1 A empresa conhece as expectativas e as necessidades atuais e futuras dos Mercados Consumidores; 3.2 - A empresa avalia e melhora seu produto em função das informações dos Mercados Consumidores; 3.3 - A empresa tem uma linha de produtos diferenciada pela qualidade; 5.3 - As informações dos clientes são utilizadas pela empresa; e 8.1 - A empresa atendeu a todas as expectativas e necessidades do Mercado Consumidor. Para o Fator 2 (Foco no fornecedor), os quesitos foram: 2.7 - A empresa busca parceria com os Mercados Fornecedores; 2.8 - São tomadas medidas em cima da busca de parceria dos Mercados Fornecedores; e 8.6 - Ranking das Empresas que melhor negociaram com o Mercado Fornecedor. 
Gráfico 1

Carga fatorial dos quesitos como função dos dois primeiros fatores

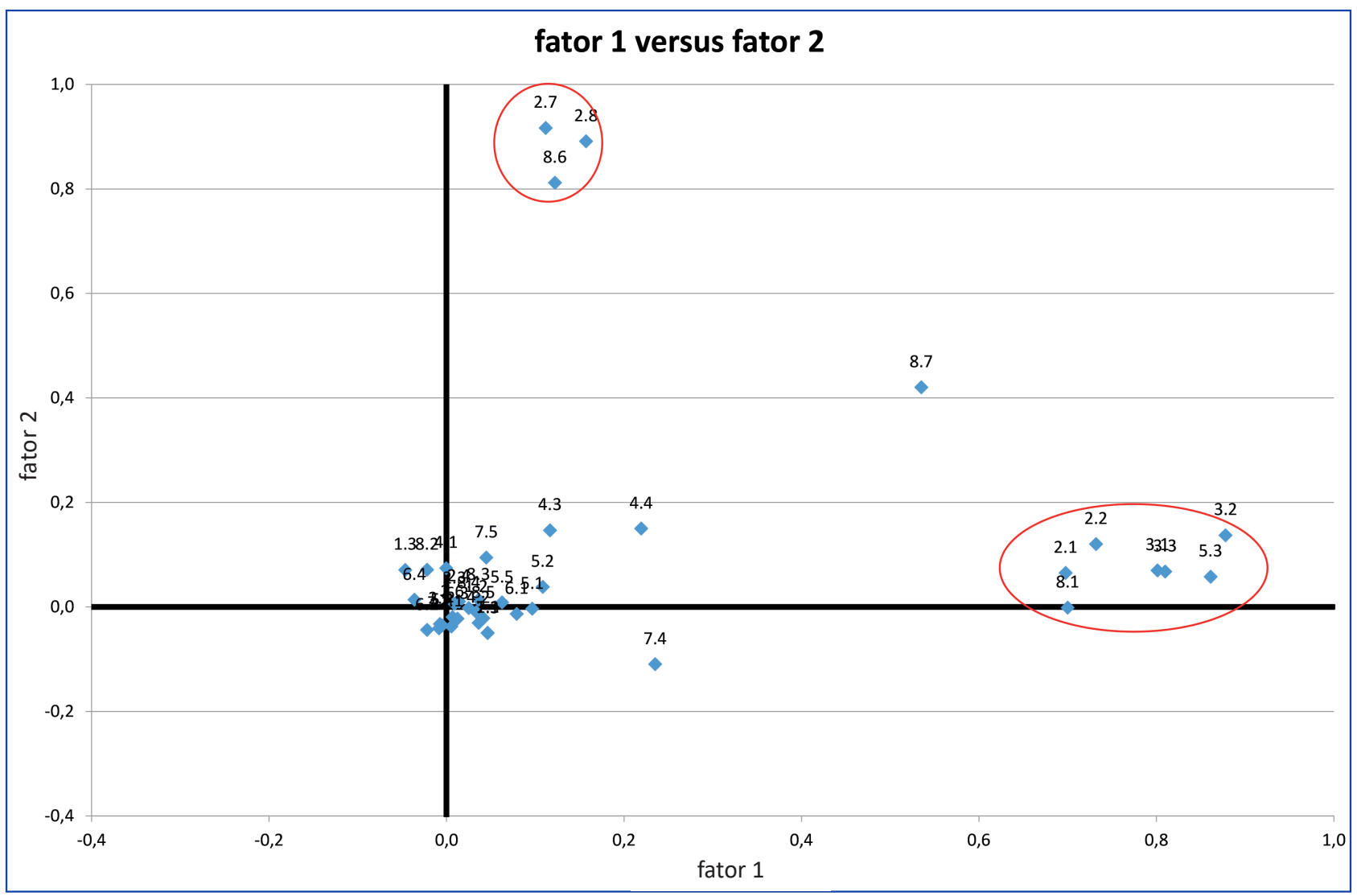

Fonte: Elaborado pelos autores.

O Gráfico 2 apresenta o Fator 1 (Foco no cliente) versus o Fator 2 (Foco no fornecedor) para as 402 empresas participantes com indicação de resultado (vencedor/outros). O que se nota é que os pontos correspondentes aos vencedores estão concentrados principalmente no primeiro e quarto quadrante, indicando que o Fator 1 parece relevante para o sucesso no JOGO, ao passo que o Fator 2, não o é. Esses fatos são corroborados nos histogramas comparativos dos fatores (ver gráficos 3 e 4) e nos testes apresentados na Tabela 3. 
Gráfico 2

Fator 1 (Foco no cliente) versus Fator 2 (Foco no fornecedor) com indicação de resultado

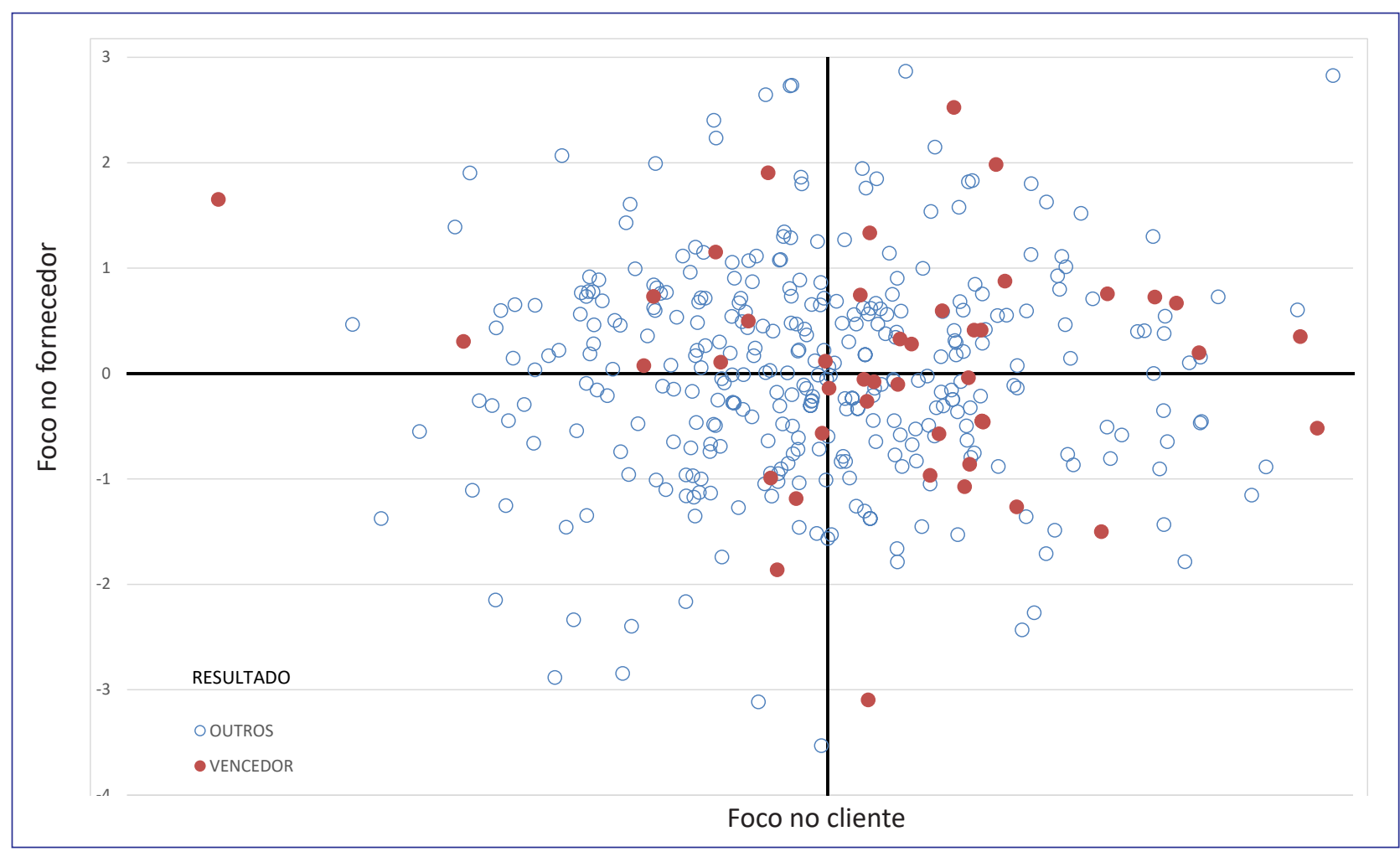

Fonte: Elaborado pelos autores.

Tabela 2

Carga fatorial dos quesitos de avaliação, avaliadores entre colchetes e pesos entre parênteses

\begin{tabular}{|c|c|c|c|c|c|c|c|c|c|c|c|c|c|c|}
\hline \multirow{2}{*}{$\begin{array}{l}\text { QUESITOS DE AVALIAÇÃO } \\
\text { [Avaliadores] (peso) }\end{array}$} & \multicolumn{14}{|c|}{ Componentes } \\
\hline & 1 & 2 & 3 & 4 & 5 & 6 & 7 & 8 & 9 & 10 & 11 & 12 & 13 & 14 \\
\hline $\begin{array}{l}\text { 1.1 A Visão definida pela alta direção é clara. } \\
\text { [CA] (8.0) }\end{array}$ &, 046 &,- 050 & ,052 & ,007 &,- 056 & ,083 & 829 &,- 008 & ,132 & ,090 & ,018 &,- 073 & ,036 & ,063 \\
\hline $\begin{array}{l}\text { 1.2 A Missão definida pela alta direção } \\
\text { considera os valores da organização, o foco } \\
\text { no cliente, o respeito e a confiança mútuos, } \\
\text { o comportamento ético, a participação das } \\
\text { pessoas e as expectativas de alto desempenho. } \\
\text { [CA] (8.0) }\end{array}$ & ,034 &,- 010 & ,017 & ,161 & ,019 &,- 018 & ,840 &,- 064 & ,159 &,- 076 & ,093 & ,018 & ,014 & ,063 \\
\hline $\begin{array}{l}1.30 \text { estilo de liderança é focado em resultados. } \\
\text { [CA] (6.0) }\end{array}$ &,- 046 & ,071 & ,278 &, 520 & ,009 & ,141 & ,322 &,- 020 &,- 060 & ,106 &,- 071 &, 121 &,- 044 & 180 \\
\hline $\begin{array}{l}2.1 \text { A empresa realiza pesquisas de satisfação } \\
\text { de clientes (pós-venda). [MC] (1.5) }\end{array}$ & 698 & ,065 &,- 069 & ,103 &,- 090 & ,254 &,- 060 &,- 128 & ,034 & ,108 &,- 292 &,- 149 & ,314 & ,062 \\
\hline $\begin{array}{l}\text { 2.2 São tomadas medidas em cima das pesquisas } \\
\text { de satisfação e das reclamações dos clientes. } \\
\text { [MC] (1.5) }\end{array}$ & ,732 &, 120 &,- 062 & ,095 &,- 108 & ,231 &,- 088 &,- 139 & ,061 & , 100 &,- 228 &,- 141 & ,296 & ,121 \\
\hline
\end{tabular}


continuação

\begin{tabular}{|c|c|c|c|c|c|c|c|c|c|c|c|c|c|c|}
\hline \multirow{2}{*}{$\begin{array}{c}\text { QUESITOS DE AVALIAÇÃO } \\
\text { [Avaliadores] (peso) }\end{array}$} & \multicolumn{14}{|c|}{ Componentes } \\
\hline & 1 & 2 & 3 & 4 & 5 & 6 & 7 & 8 & 9 & 10 & 11 & 12 & 13 & 14 \\
\hline $\begin{array}{l}2.3 \text { A empresa busca parceria com seus } \\
\text { concorrentes. [CA] (1.5) }\end{array}$ & ,009 & ,006 & 150 & ,036 &,- 110 & 189 &,- 139 & , 146 & ,226 &,- 324 &,- 045 &,- 448 &,- 123 & ,316 \\
\hline $\begin{array}{l}\text { 2.4 A empresa toma ações em função da análise } \\
\text { dos concorrentes. [CA] (1.5) }\end{array}$ & ,014 & ,010 & ,754 & ,013 & ,029 &,- 098 & ,022 & ,038 & ,255 & ,093 & ,074 & ,085 & 127 & , 105 \\
\hline $\begin{array}{l}\text { 2.5 A empresa analisa o ambiente competitivo } \\
\text { em busca de novas oportunidades. [CA] (1.5) }\end{array}$ &,- 007 &,- 033 & ,814 & ,239 &,- 019 & ,056 & ,038 &,- 002 &,- 023 & 130 &,- 012 &,- 050 & ,027 & ,015 \\
\hline $\begin{array}{l}\text { 2.6 São tomadas ações em relação à análise } \\
\text { do ambiente competitivo. [CA] (1.5) }\end{array}$ & ,007 &,- 019 & ,820 & 167 & ,092 &,- 079 & ,036 & ,055 &,- 053 &,- 023 &,- 037 & , 046 &,- 077 &,- 041 \\
\hline $\begin{array}{l}\text { 2.7 A empresa busca parceria com os Mercados } \\
\text { Fornecedores. [MF] (1.5) }\end{array}$ & 112 & ,917 &,- 005 &,- 038 &,- 079 & ,035 & ,000 &,- 014 &,- 001 & ,055 &,- 007 &,- 040 & ,056 & ,007 \\
\hline $\begin{array}{l}\text { 2.8 São tomadas medidas em cima da busca de } \\
\text { parceria dos Mercados Fornecedores. [MF] (1.5) }\end{array}$ & 157 & ,891 &,- 012 & ,013 & ,003 & 103 &,- 001 & ,027 & ,064 & 049 &,- 016 &,- 080 & ,041 & ,015 \\
\hline $\begin{array}{l}\text { 3.1 A empresa conhece as expectativas e as } \\
\text { necessidades atuais e futuras dos Mercados } \\
\text { Consumidores (pré-venda). [MC] (1.5) }\end{array}$ & 801 & ,070 & ,028 &,- 013 & 105 & ,042 & ,058 & 160 &,- 014 & ,005 & ,070 &,- 057 &,- 019 &,- 095 \\
\hline $\begin{array}{l}\text { 3.2 A empresa avalia e melhora seu produto } \\
\text { em função das informações dos Mercados } \\
\text { Consumidores. [MC] (4.0) }\end{array}$ & ,878 & 137 & ,035 & ,023 & ,005 & ,086 & ,015 & ,013 &,- 019 & ,006 & ,028 & ,073 & ,036 & ,036 \\
\hline $\begin{array}{l}\text { 3.3 A empresa tem uma linha de produtos } \\
\text { diferenciada pela qualidade. [MC] (4.0) }\end{array}$ & 810 & ,068 & 033 & ,001 &,- 057 & 015 &,- 014 &,- 082 & 099 & ,053 &,- 002 & 195 &,- 028 & ,057 \\
\hline $\begin{array}{l}\text { 4.1 As pessoas da força de trabalho, fornece- } \\
\text { dores e outras partes interessadas são cons- } \\
\text { cientizadas e envolvidas em questões relativas à } \\
\text { responsabilidade social e ambiental? [CA] (3.0) }\end{array}$ & 000 & 074 & 016 & 169, &,- 064 & 013 & 142 &,- 045 & 745 & ,086 & -102 & ,041 & ,092 &,- 043 \\
\hline $\begin{array}{l}\text { 4.2 A empresa tem um código de ética esta- } \\
\text { belecido. [CA] (3.0) }\end{array}$ & ,036 &,- 031 & ,058 &,- 007 &,- 006 & 079, & 172 & 001 & 743 & ,009 & 075 &,- 077 &,- 137 & 135 \\
\hline $\begin{array}{l}4.3 \text { A empresa comunica à sociedade os } \\
\text { impactos e respectivas informações associadas } \\
\text { aos produtos, processos e instalações? [T] (3.0) }\end{array}$ & 117 & 147, &,- 003 & ,008 &,- 030 & 911 & ,082 &,- 034 & 079 & ,002 & ,002 & ,064 &,- 043 & ,062 \\
\hline $\begin{array}{l}\text { 4.4 O grau de satisfação da comunidade com } \\
\text { a empresa é identificado e avaliado? [T] (3.0) }\end{array}$ & 219 & 150, &,- 119 &,- 009 &,- 019 & 894 & 013 & 018 & ,032 & ,040 & ,038 &,- 022 & 011 &,- 010 \\
\hline $\begin{array}{l}5.1 \text { As informações relativas aos concorrentes } \\
\text { são utilizadas pela empresa. [CA] (2.0) }\end{array}$ & 097 &,- 003 & 365 &,- 048 & 106 & 059 &,- 021 & ,014 & 420 & 194 & 392 &,- 066 &,- 017 & -176 \\
\hline $\begin{array}{l}5.2 \text { As informações relativas à qualidade do } \\
\text { produto são utilizadas pela empresa. [CA] (2.0) }\end{array}$ & 108 & ,038 & ,036 & ,051 & ,053 & ,014 &,- 024 &,- 007 & ,085 & 785 &,- 001 & ,058 & 076 & 258 \\
\hline $\begin{array}{l}\text { 5.3 As informações dos clientes são utilizadas } \\
\text { pela empresa. [MC] (3.0) }\end{array}$ & 861 & ,058 &,- 037 &,- 043 & ,057 &,- 002 & 083 & ,037 &,- 013 & ,004 & 090 &,- 016 &,- 140 & ,005 \\
\hline $\begin{array}{l}\text { 5.4 As informações relativas ao desempenho } \\
\text { operacional são utilizadas pela empresa. [CA] (2.0) }\end{array}$ &,- 005 &,- 035 & 188 & 190, &,- 010 & ,064 & 074 & 178 & 055 & 731 & 090 &,- 022 &,- 074 &,- 065 \\
\hline $\begin{array}{l}5.5 \text { As informações relativas ao desempenho } \\
\text { financeiro são utilizadas pela empresa. [CA] (3.0) }\end{array}$ & 063 & 009 & 114 & 402 & 132 &,- 036 &,- 093 & ,062 & 341 & ,386 &,- 043 & 126 &,- 226 &,- 177 \\
\hline $\begin{array}{l}\text { 6.1 As pessoas estão satisfeitas com o que } \\
\text { fazem. [CA] (4.5) }\end{array}$ & 079 &,- 013 & ,069 & 729 & 126 & 020 & ,053 & 097 & ,044 & 122 & ,080 &,- 008 &,- 068 &,- 026 \\
\hline $\begin{array}{l}\text { 6.2 A área de Negócio tem autonomia para } \\
\text { atuar. [CA] (4.5) }\end{array}$ &,- 022 &,- 044 & 140 & 601 &,- 030 &,- 004 & 126 & ,082 &,- 049 & 131 & 292 &,- 119 & ,085 & -265 \\
\hline $\begin{array}{l}\text { 6.3 A área de Produção tem autonomia para } \\
\text { atuar. [CA] (4.5) }\end{array}$ & ,012 &,- 022 &,- 025 & 179, &,- 103 & ,040 & 113 &,- 045 &,- 046 & ,051 & 797 &,- 062 & ,056 & ,056 \\
\hline $\begin{array}{l}\text { 6.4 A comunicação entre as Áreas de Negócio } \\
\text { e de Produção é clara, objetiva e sem ruídos. } \\
\text { [CA] (4.5) }\end{array}$ &,- 036 & ,014 & 018 & ,364 & ,042 &,- 009 &,- 133 &,- 097 & 251 &,- 070 & ,445 & ,235 & 215 & ,460 \\
\hline
\end{tabular}


continuação

\begin{tabular}{|c|c|c|c|c|c|c|c|c|c|c|c|c|c|c|}
\hline \multirow{2}{*}{$\begin{array}{l}\text { QUESITOS DE AVALIAÇÃO } \\
\text { [Avaliadores] (peso) }\end{array}$} & \multicolumn{14}{|c|}{ Componentes } \\
\hline & 1 & 2 & 3 & 4 & 5 & 6 & 7 & 8 & 9 & 10 & 11 & 12 & 13 & 14 \\
\hline $\begin{array}{l}7.1 \text { Melhor preço médio pago na compra de } \\
\text { matéria-prima (Mercado Fornecedor). [J] (4.5) }\end{array}$ & ,006 &,- 037 & ,065 &,- 017 & ,243 &,- 050 & ,051 & 153 &,- 065 &,- 024 & 101 & ,058 & 797 &,- 106 \\
\hline $\begin{array}{l}\text { 7.2 Melhor preço médio recebido na venda } \\
\text { de matéria-prima no produto (Mercado } \\
\text { Consumidor). [J] (4.5) }\end{array}$ &,- 008 &,- 041 & ,028 & ,047 & ,894 &,- 014 &,- 033 &,- 031 & ,058 & ,066 &,- 027 &,- 040 &,- 043 &,- 024 \\
\hline $\begin{array}{l}\text { 7.3 Valor agregado ao produto (Preço produto } \\
\text { final vendido / custo da matéria-prima adqui- } \\
\text { rida). [J] (4.5) }\end{array}$ & ,046 &,- 050 & ,031 & ,055 & ,852 & ,008 & ,013 & ,078 &,- 019 & ,058 &,- 005 & ,049 & ,301 &,- 060 \\
\hline $\begin{array}{l}\text { 7.4 Lead time de entrega (período decorrido } \\
\text { a partir do momento em que o comprador } \\
\text { confirmou a compra até recebê-lo em suas } \\
\text { mãos). [MC] (4.5) }\end{array}$ & ,235 &,- 110 & 114 & ,070 & ,008 & 101 &,- 100 & ,128 & , 010 & ,018 &,- 073 & ,776 & ,028 & ,023 \\
\hline $\begin{array}{l}\text { 7.5 Os critérios utilizados para selecionar } \\
\text { e qualificar fornecedores são claros e bem } \\
\text { definidos. [CA] (4.0) }\end{array}$ & ,045 & ,095 & , 047 & ,041 & ,018 & ,059 & ,304 & ,027 &,- 016 & ,241 & ,031 &,- 104 &,- 158 & ,681 \\
\hline $\begin{array}{l}\text { 8.1 A empresa atendeu a todas as expectativas } \\
\text { e necessidades do Mercado Consumidor. } \\
\text { [MC] (20.0) }\end{array}$ & ,700 &,- 001 &,- 006 & ,026 &,- 004 &,- 012 & ,035 & ,084 & ,021 &,- 071 & ,029 & ,388 &,- 100 &,- 086 \\
\hline 8.2 Rentabilidade. [J] (22.0) &,- 022 & ,071 & 077 & ,063 &, 545 &,- 057 &,- 021 & ,349 &,- 117 &,- 074 &,- 060 & ,059 & ,020 & 143 \\
\hline 8.3 Participação Física (vendas físicas). [J] (8.0) & ,036 & ,014 & ,045 & ,036 &,- 057 &,- 018 &,- 039 & 878 &,- 020 & ,044 & ,009 & ,102 & ,152 &,- 016 \\
\hline $\begin{array}{l}\text { 8.4 Participação Financeira (vendas financeiras). } \\
\text { [J] (8.0) }\end{array}$ & ,025 &,- 002 & ,021 & ,099 & ,292 & ,016 &,- 032 & 792 & ,009 & ,123 &,- 052 &,- 030 &,- 034 & ,005 \\
\hline $\begin{array}{l}\text { 8.5 A Empresa tem um excelente clima } \\
\text { organizacional. [CA] (6.0) }\end{array}$ & ,041 &,- 022 & 134 & ,748 & ,008 &,- 055 &,- 020 & ,004 & 151 &,- 026 & ,029 & ,061 & ,060 & 208 \\
\hline $\begin{array}{l}\text { 8.6 Ranking das Empresas que melhor nego- } \\
\text { ciaram com o Mercado Fornecedor. [MF] (10.0) }\end{array}$ & 122 & ,812 &,- 045 &,- 018 & ,029 & 149 &,- 049 & ,005 &,- 008 &,- 113 &,- 028 & ,011 &,- 128 & ,059 \\
\hline $\begin{array}{l}\text { 8.7 Considerando todos os quesitos avaliados, } \\
\text { a nota que você atribuí a Empresa? [T] (16.0) }\end{array}$ & ,535 & ,421 & 161 & 115, & ,052 & 377 &,- 004 & ,049 &,- 067 & 105 & 135 & ,049 &,- 032 & ,029 \\
\hline
\end{tabular}

Legenda: $[\mathrm{CA}]$ = Comitê de Auditores; $[\mathrm{MC}]$ = Mercados Consumidores; $[\mathrm{MF}]$ = Mercados Fornecedores; $[\mathrm{T}]$ = Todos; e $[\mathrm{J}]$ = Resultado do Jogo. Fonte: Elaborada pelos autores.

A Tabela 3 apresenta o teste de Levene para igualdades de variâncias e teste $t$ para igualdades de médias comparando os 2 subgrupos (vencedores e outros participantes) correspondentes ao resultado do JOGO para cada um dos 14 fatores identificados. A informação da diferença das variâncias é necessária para determinar o teste $t$ que será utilizado: sob a hipótese de igualdade de médias ou não. $O$ teste para diferença de médias apresentado na Tabela 3 indica que existe diferença estatisticamente significativa entre vencedores e os outros participantes para o Fator 1 - Foco no cliente e não para o Fator 2. O p-valor (bicaudal) combinado com a estatística $t$ serve para mostrar a importância relativa dos fatores. Nesse caso, os mais importantes foram os fatores 5, 8, 4, 3 e 12, seguidos pelo Fator 1 .

A Tabela 3 também apresenta um resumo dessa análise na primeira coluna, junto com a descrição dos fatores. Fatores seguidos de (M) apresentam diferenças de médias, entre vencedores e outros participantes, estatisticamente significativas. Fatores seguidos de (V) apresentam diferenças de variância entre vencedores e demais participantes estatisticamente significativas. Os fatores sem indicação não apresentam diferenças significativas nem entre médias nem entre variâncias. 
Tabela 3

Teste de Levene para igualdades de variâncias $(\alpha=5 \%)$ e teste $t$ para igualdades de médias

\begin{tabular}{|c|c|c|c|c|c|c|c|c|c|}
\hline \multirow{2}{*}{ FATOR } & \multicolumn{2}{|c|}{$\begin{array}{c}\text { Teste de Levene } \\
\text { para igualdade de } \\
\text { variâncias }\end{array}$} & \multicolumn{7}{|c|}{ Teste t para igualdade de médias } \\
\hline & $\mathrm{F}$ & p-valor & $\mathrm{t}$ & gl & $\begin{array}{l}\text { p-valor } \\
\text { (bicaudal) }\end{array}$ & $\begin{array}{l}\text { Diferença } \\
\text { de médias }\end{array}$ & $\begin{array}{c}\text { Desvio } \\
\text { padrão da } \\
\text { diferença }\end{array}$ & $\begin{array}{l}\text { IC Inferior } \\
95 \%\end{array}$ & $\begin{array}{l}\text { IC Superior } \\
95 \%\end{array}$ \\
\hline 1- Foco no cliente (M) & 0,784 & 0,236 & $-3,293$ & 400 & 0,001 & $-0,50502$ & 0,15335 & $-0,80650$ & $-0,20355$ \\
\hline 2- Foco no fornecedor & 0,939 & 0,733 & $-0,212$ & 400 & 0,832 & $-0,03299$ & 0,15541 & $-0,33851$ & 0,27252 \\
\hline $\begin{array}{l}\text { 3- Considera o ambiente } \\
\text { competitivo (M) }\end{array}$ & 1,219 & 0,416 & $-3,941$ & 400 & 0,000 & $-0,60091$ & 0,15248 & $-0,90068$ & $-0,30114$ \\
\hline $\begin{array}{l}4 \text { - Satisfação de } \\
\text { trabalhadores (VM) }\end{array}$ & 2,672 & 0,000 & $-4,253$ & 82,954 & 0,000 & $-0,45399$ & 0,10675 & $-0,66632$ & $-0,24166$ \\
\hline $\begin{array}{l}\text { 5- Indicadores } \\
\text { financeiros de vendas } \\
\text { (VM) }\end{array}$ & 3,984 & 0,000 & $-7,299$ & 103,582 & 0,000 & $-0,67403$ & 0,09235 & $-0,85716$ & $-0,49089$ \\
\hline $\begin{array}{l}\text { 6- Informações para a } \\
\text { sociedade }\end{array}$ & 0,978 & 0,877 & $-1,002$ & 400 & 0,317 & $-0,15549$ & 0,15522 & $-0,46063$ & 0,14966 \\
\hline 7- Visão \& Missão (M) & 1,559 & 0,067 & $-2,160$ & 400 & 0,031 & $-0,33378$ & 0,15452 & $-0,63755$ & $-0,03002$ \\
\hline $\begin{array}{l}\text { 8- Participação de vendas } \\
\text { (VM) }\end{array}$ & 1,760 & 0,021 & $-5,094$ & 69,442 & 0,000 & $-0,62575$ & 0,12283 & $-0,87077$ & $-0,38074$ \\
\hline $\begin{array}{l}\text { 9- Responsabilidade e } \\
\text { ética }\end{array}$ & 0,725 & 0,118 & $-0,636$ & 400 & 0,525 & $-0,09876$ & 0,15534 & $-0,40413$ & 0,20662 \\
\hline $\begin{array}{l}\text { 10- Feedback sobre } \\
\text { qualidade produto }\end{array}$ & 1,578 & 0,060 & $-1,665$ & 400 & 0,097 & $-0,25790$ & 0,15488 & $-0,56238$ & 0,04657 \\
\hline $\begin{array}{l}\text { 11- Autonomia de } \\
\text { produção }\end{array}$ & 1,413 & 0,152 & $-1,578$ & 400 & 0,115 & $-0,24445$ & 0,15493 & $-0,54904$ & 0,06013 \\
\hline 12 - Lead time (VM) & 1,745 & 0,023 & $-3,881$ & 69,232 & 0,000 & $-0,48230$ & 0,12427 & $-0,73019$ & $-0,23441$ \\
\hline 13- Custo de insumos & 1,456 & 0,120 & $-1,772$ & 400 & 0,077 & $-0,27431$ & 0,15481 & $-0,57865$ & 0,03003 \\
\hline $\begin{array}{l}\text { 14- Seleção de } \\
\text { fornecedores }\end{array}$ & 0,693 & 0,074 & $-0,837$ & 400 & 0,403 & $-0,12996$ & 0,15528 & $-0,43523$ & 0,17530 \\
\hline
\end{tabular}

Nota: Entre parênteses após o nome do fator, o $\mathrm{M}$ indica significância estatística na diferença das médias de vencedores e demais participantes. $V$ indica significância estatística entre as variâncias de vencedores e demais participantes.

Fonte: Elaborada pelos autores.

Para complementar a análise, o Gráfico 3 apresenta uma comparação dos histogramas do Fator 1 - Foco no cliente, segundo resultado no JOGO. Esses são histogramas duplos com vencedores do lado direito e outros participantes do lado esquerdo. Como se observa no Gráfico 3, vencedores apresentam uma distribuição com valores tipicamente maiores do que os outros participantes, caracterizando ser esse um fator determinante para o sucesso final no JOGO. Isso é confirmado por um teste estatístico. Para esse fator, nota-se uma diferença estatisticamente significativa das médias segundo o resultado, mas não das variâncias (ver Tabela 3). Como se observa no Gráfico 4, a distribuição dos valores do Fator 2 (Foco no fornecedor) para vencedores é bem semelhante à observada para outros participantes, caracterizando não haver diferenças entre as médias, e que esse não é um fator determinante para o sucesso final. Visualmente, o conceito é reforçado pelo fato de que a amplitude para vencedores (lado direito do gráfico) também é semelhante à observada para outros participantes (lado esquerdo). Isso é confirmado por um teste estatístico (ver Tabela 3). Esses resultados corroboram a descrição do Gráfico 2, complementando os comentários do Gráfico 3 e do Gráfico 4. 


\section{Gráfico 3}

Histogramas do Fator 1 - Foco no Cliente, segundo o resultado no JOGO

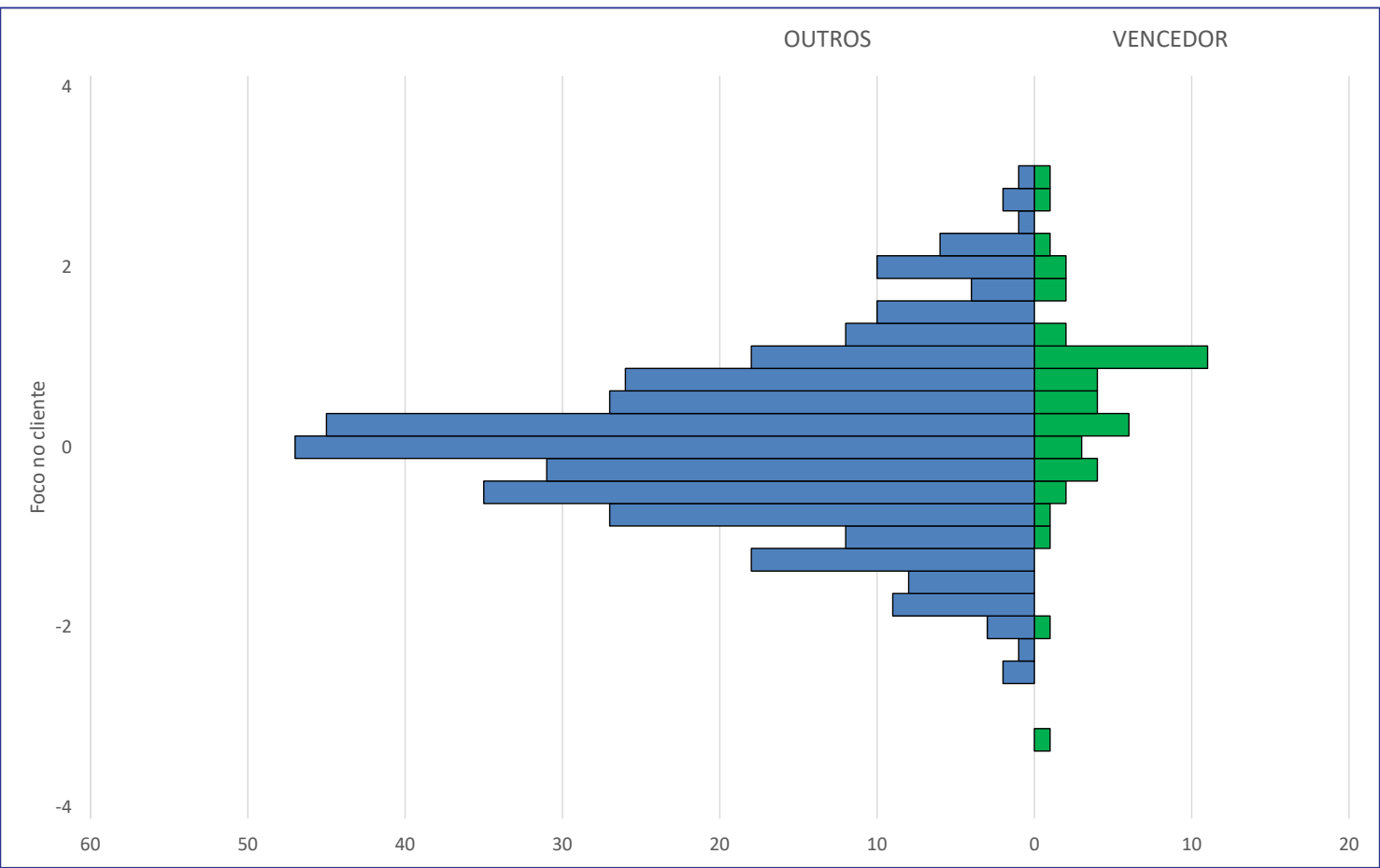

Fonte: Elaborado pelos autores.

Gráfico 4

Histogramas do Fator 2 - Foco no Fornecedor, segundo o resultado no JOGO

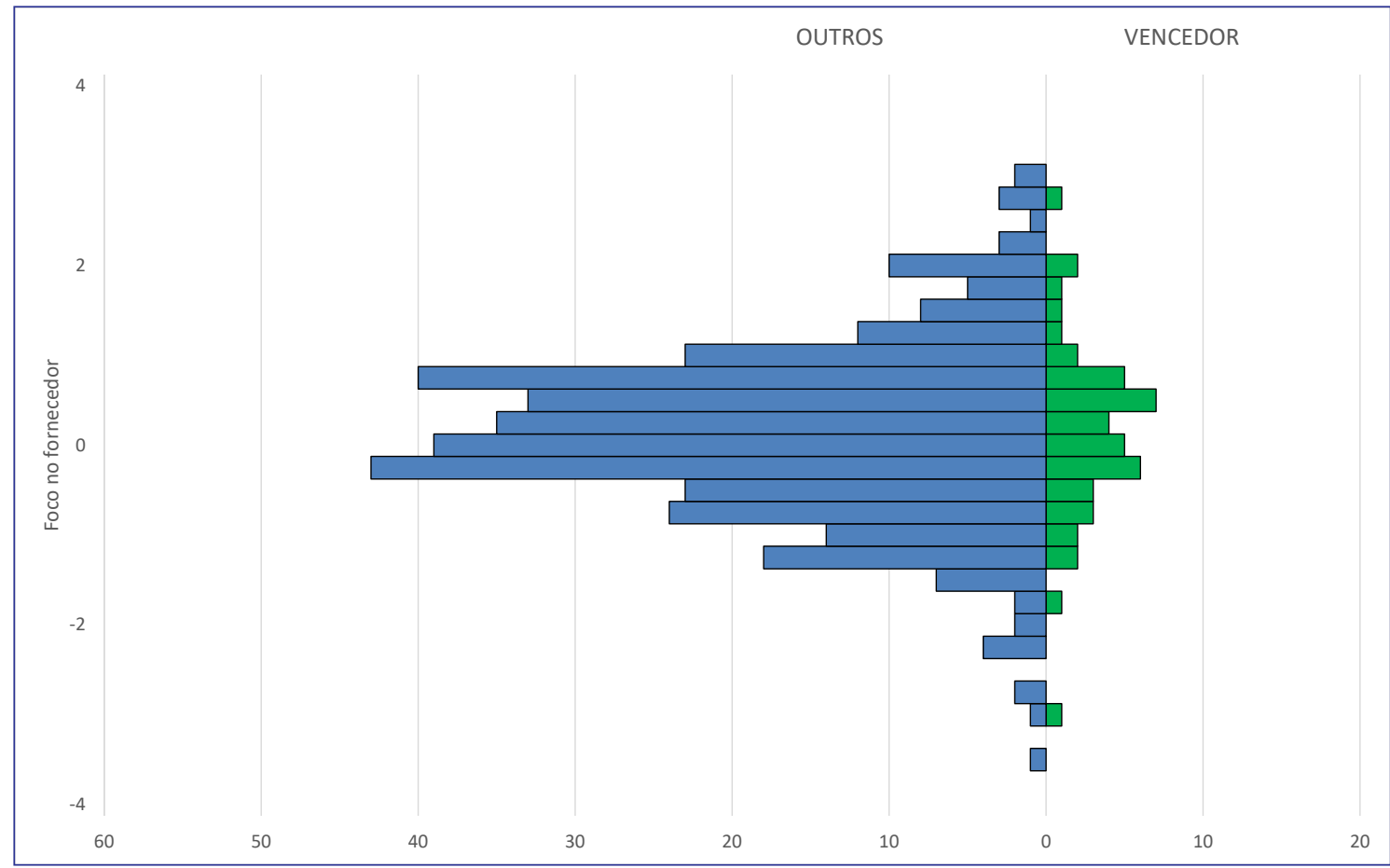

Fonte: Elaborado pelos autores. 


\section{Modelo linear generalizado}

Para explicar o sucesso/fracasso no JOGO, ajustou-se um modelo linear generalizado (MLG) utilizando como variáveis explicativas os fatores identificados na AF, função de ligação logito e uma distribuição Bernouilli. Das 402 equipes de estudantes analisadas na modelagem, 47 foram vencedoras. A Tabela 4 apresenta a lista de fatores testados como variáveis explicativas. Considerando o nível de confiança, a, de 5\%, não são estatisticamente significativos os fatores 2, 6, 9, 11 e 14. Comparando essa lista de fatores significativos com os da Tabela 3, nota-se que as únicas discrepâncias são os fatores 10 e 13, que aparecem como significativos na Tabela 4 e não na Tabela 3 (ainda que fossem significativos a 10\%). A Tabela 4 também apresenta os coeficientes associados aos fatores, bem como os intervalos de confiança (IC) de $95 \%$. A estatística do qui-quadrado de Wald serve, ainda, para mostrar a importância relativa dos fatores no modelo ajustado. Nesse caso, os mais importantes foram: fatores 5, 8, 4, 3 e 12 (valor $p$ igual a 0,000). Em seguida vem o fator 1 e o fator 13.

Tabela 4

Teste de efeitos do modelo, parâmetros e IC de $95 \%$

\begin{tabular}{c|c|c|c|c|c|c}
\hline \multirow{2}{*}{ Fonte } & \multicolumn{3}{|c|}{ Tipo III } & \multicolumn{2}{c}{ IC 95\% de Wald } \\
\cline { 2 - 7 } & $\begin{array}{c}\text { Qui-quadrado } \\
\text { de Wald }\end{array}$ & g.l. & Valor $\boldsymbol{p}$ & parâmetro & Inferior & Superior \\
\hline fator 1 & 8,242 & 1 &, 004 & 4,134 & 3,208 & 5,061 \\
\hline fator 2 &, 318 & 1 &, 573 & 0,625 & 0,198 & 1,051 \\
\hline fator 3 & 15,056 & 1 &, 000 & $-0,114$ & $-0,510$ & 0,282 \\
\hline fator 4 & 15,700 & 1 &, 000 & 0,873 & 0,432 & 1,314 \\
\hline fator 5 & 21,890 & 1 &, 000 & 1,469 & 0,742 & 2,195 \\
\hline fator 6 &, 303 & 1 &, 582 & 1,844 & 1,071 & 2,616 \\
\hline fator 7 & 7,249 & 1 &, 007 & 0,131 & $-0,336$ & 0,598 \\
\hline fator 8 & 17,490 & 1 &, 000 & 0,592 & 0,161 & 1,023 \\
\hline fator 9 &, 120 & 1 &, 729 & 1,214 & 0,645 & 1,783 \\
\hline fator 10 & 4,362 & 1 &, 037 & 0,068 & $-0,315$ & 0,450 \\
\hline fator 11 & 3,715 & 1 &, 054 & 0,526 & 0,032 & 1,020 \\
\hline fator 12 & 13,613 & 1 &, 000 & 0,449 & $-0,008$ & 0,905 \\
\hline fator 13 & 3,841 & 1 &, 050 & 0,981 & 0,460 & 1,502 \\
\hline fator 14 &, 023 & 1 &, 879 & 0,547 & $-4,237 \mathrm{E}-5$ & 1,093 \\
\hline
\end{tabular}

Fonte: Elaborada pelos autores.

\section{COMENTÁRIOS E CONCLUSÕES}

Métodos e técnicas de ensino-aprendizagem podem ser focados no professor ou no aluno. A meta de ambos é a mesma: passar ou reforçar um conjunto de conhecimentos. No entanto, habilidades e atitudes dos alunos, acredita-se, são mais bem desenvolvidas quando eles se tornam os atores principais do método de ensino, um processo de aprendizagem vivencial.

Não existe na literatura consenso sobre qual seria o melhor método para uma tarefa específica. Esse também é o caso de jogos de negócio enquanto método de ensino para integração de conhecimentos. É importante notar que seria difícil conduzir um curso utilizando unicamente jogos de negócio, mas o método tem se mostrado eficaz como complemento de outros mais tradicionais, tais como aulas expositivas (VERSIANI e FACHIN, 2007).

O método proposto e analisado neste artigo cobre uma variedade de aspectos: variáveis qualitativas (avaliadas por pares) e quantitativas, opiniões e sentimentos dos alunos, integração de dois domínios do processo de aprendizagem, os aspectos cognitivos e comportamentais (soft skills). A conexão entre a realidade e o modelo alimenta o processo de aprendizagem e 
a integração de conhecimentos. O JOGO pode ser visto tanto como um método de integração de conhecimentos quanto de avaliação do aprendizado.

É verdade que não se pode determinar qual etapa do processo de ensino-aprendizagem é responsável pelo hiato entre a nota máxima alcançável e a realmente obtida durante o JOGO pelas equipes. O hiato pode dever-se a várias razões: i) o conceito não foi ensinado durante a vida escolar/profissional pregressa do aluno, inclusive no MBA que está cursando; ii) foi ensinado, mas não foi apreendido; iii) foi apreendido, mas os alunos tiveram problemas para aplicá-lo integradamente. Reconhecer a existência do hiato, no entanto, deve ser o primeiro passo para eliminá-lo.

Do ponto de vista qualitativo, a partir do feedback dos alunos, mesmo considerando não serem estes homogêneos, pode-se dizer que os alunos do JOGO (em oposição aos de aulas expositivas) são mais participativos, mais comprometidos com o processo de aprendizagem, mais conscientes de seus pontos fracos e fortes, mais engajados nas equipes e tendo uma atitude mais empreendedora. Outros pontos positivos são melhora do moral dos estudantes e aumento de interesse pelo assunto, redução do absenteísmo, criação de um ambiente favorável a discussões sobre ética nos negócios, motivação dos participantes a procurar aprofundar os conhecimentos e, finalmente, como a avaliação do JOGO é feita por outros alunos, o resultado final raramente é contestado.

O processo de tomada de decisão é algo intrínseco em um jogo de negócio, portanto, os estudantes se sentem responsáveis por suas ações. Uma decisão errada pode afetar o resultado da equipe caso a equipe não a perceba a tempo. Porém, o JOGO possibilita, por meio de sua dinâmica, uma correção compensatória do erro. Os estudantes têm uma única oportunidade para ganhar o JOGO - a jogada, diferentemente de jogos eletrônicos que podem ser reiniciados ad infinitum.

Percebe-se que os aspectos comportamentais do processo de aprendizagem (p. ex., a aceitação de seu papel), os aspectos psicomotores (p. ex., manuseio dos pinos para criar joias), a avaliação por pares e o conhecimento prévio adquirido por meio do curso são fatores que afetam o resultado do JOGO e a visão dos estudantes do hiato entre a teoria e a prática.

Do ponto de vista quantitativo, a análise mostra que alguns fatores não são determinantes do resultado final do JOGO: a distribuição dos valores dos vencedores é similar à dos demais participantes. Outros fatores apresentam valores com menor variância para os vencedores do que para os outros. Vale notar que esses resultados se referem à amostra em estudo. São várias as alternativas que podem explicar a ausência de diferença estatisticamente significativa entre vencedores e demais participantes para algum fator: alguns processos podem já ter sido internalizados por todos os estudantes (p. ex., Foco no fornecedor), alguns podem ser tão teórico-conceituais que não constituem uma preocupação real dos estudantes (p. ex., Responsabilidade e ética) e outros envolvem um grau de julgamento de valor (p. ex., Informações para a sociedade), possivelmente não passíveis de ser plenamente avaliados no jogo. Além disso, alguns são de tal modo controlados pelo facilitador do jogo (O Governo) que o comportamento das equipes tende a ser ético e, portanto, razoavelmente uniforme (p. ex., Responsabilidade e ética).

Finalmente, existem fatores que são determinantes para o sucesso no JOGO. Esse foi o caso dos fatores 5 (Indicadores financeiros de vendas), 8 (Participação de vendas), 4 (Satisfação de trabalhadores), 3 (Considera o ambiente competitivo), 12 (Lead time), 1 (Foco no cliente) e 13 (Custo de insumos). 


\section{REFERÊNCIAS}

ALESSI, S. Fidelity in the design of instructional simulations. Journal of Computer-Based Instruction, v. 15, n. 2, p. 40-47, 1988.

BARÇANTE, L. C.; CORREA, C. J. O jogo master de gestão da qualidade total. In: ENCONTRO NACIONAL DE ENGENHARIA DE PRODUÇÃO, 21., 2001, Salvador. Anais... Salvador: ABEPRO, 2001. Disponível em: <http://www.abepro.org.br/biblioteca/ENEGEP2001_TR65_0866. pdf>. Acesso em: 20 out. 2016.

BARÇANTE, L. C.; PITHON, A. J. C.; BROCHADO, M. R. A vez e a hora da administração industrial jogar - Jogai Cefet. In: ENCONTRO NACIONAL DE ENGENHARIA DE PRODUÇÃO, 30., 2010, São Carlos. Anais... São Carlos, SP: ABEPRO, 2010.

BELTRÃO. K. I.; BARÇANTE, L. C. Teaching principles and fundamentals of business excellence to undergraduate students through a game. Total Quality Management and Business Excellence, v. 26, p. 1-18, 2015.

BIGGS, J. Teaching for quality learning at university. Buckingham: Open University Press, 1999.

BRAGGE, J.; THAVIKULWAT, P.; TÖYLI, J. Profiling 40 years of research in simulation \& gaming. Simulation \& Gaming: An Interdisciplinary Journal, v. 41, n. 6, p. 869-897, 2011.

CONGRESSO BRASILEIRO DE ENGENHARIA - COBENGE. COBENGES anteriores. [2017]. Disponível em: <http://www.abenge.org.br/ cobenge.php>. Acesso em: 28 out. 2017.

DAVIS, E. S. M. Aligning products with supply chain processes and strategy. The International Journal of Logistics Management, v. 21, n. 1, p. 127-151, 2010.

ELGOOD, C. Handbook of management games. 5. ed. Aldershot: Gower, 1993.

ENCONTRO NACIONAL DA ASSOCIAÇÃO NACIONAL DE PÓSGRADUAÇÃO E PESQUISA EM ADMINISTRAÇÃO - ENANPAD. Outras edições. [2017]. Disponível em: <http://www.anpad.org.br/ anpad/ eventos.php?cod_evento=1>. Acesso em: 28 out. 2017.

ENCONTRO NACIONAL DE ENGENHARIA DE PRODUÇÃO - ENEGEP. Anais do Encontro Nacional de Engenharia de Produção. [2017]. Disponível em: <http://www.abepro.org.br/publicacoes/>. Acesso em: 28 out. 2017

ENCONTRO NACIONAL DOS CURSOS DE GRADUAÇÃO EM ADMINISTRAÇÃO - ENANGRAD. Anais do Encontro Nacional dos Cursos de Graduação em Administração. [2017]. Disponível em: <http:// www.angrad.org.br/eventos/enangrad/>. Acesso em: 28 out. 2017.

FARIA, A. The changing nature of business simulation/gaming research: A brief history. Simulation \& Gaming: An Interdisciplinary Journal, v. 32 , n. 1, p. 97-110, 2001.

FARIA, A. J.; HUTCHINSON, D.; WELLINGTON, W. J. Developments in business gaming: a review of the past 40 years. Simulation \& Gaming: An Interdisciplinary Journal, v. 40, n. 4, p. 464-487, 2009.

FUNDAÇÃO NACIONAL DA QUALIDADE - FNQ. Critérios de excelência: avaliação e diagnóstico da gestão organizacional. São Paulo: FNQ, 2013.

FUNDAÇÃO NACIONAL DA QUALIDADE - FNQ. Modelo de Excelência da Gestão (MEG): guia de referência de excelência da gestão. São Paulo: FNQ, 2016.
GENTRY, J. Guide to business gaming and experiential learning. London: Kogan Page, 1990.

GOSEN, J. The influence of variables easily controlled by the instructor/ administrator on simulation outcomes: in particular, the variable reflection. Developments in Business Simulation and Experiential Learning, v. 31, p. 318-324, 2004.

GOSEN, J.; WASHBUSH, J. A review of scholarship on assessing experiential learning effectiveness. Simulation \& Gaming: An Interdisciplinary Journal, v. 35, n, 2, p. 270-293, 2004.

GROSSLER, A. Don't let history repeat itself: methodological issues concerning the use of simulators in teaching and experimentation. System Dynamics Review, v. 20, n. 3, p. 263-274, 2004.

HALL, J. Computer simulation: a design architectronic. Developments in Business Simulation and Experiential Learning, v. 31, p. 166175, 2004.

KNOWLES, M. S. The modern practice of adult education: from pedagogy to andragogy. 2. ed. New York: Cambridge Books, 1980.

KOLB, D. A. Experiential learning: experience as the source of learning and development. Upper Saddle River, NJ: Prentice Hall, 1984.

LU, D.; BETTS, A.; CROOM, S. Re-investigating business excellence: values, measures and a framework. Total Quality Management \& Business Excellence, v. 22, n. 12, p. 1263-1276, 2013.

MALIK, D.; HOWARD, B. How do we know where we are going if we don't know where we have been: a review of business simulation research. Developments in Business Simulation and Experiential Learning, v. 23, p. 49-53, 1996.

MOHAMMAD, M. et al. Business excellence model: an overarching framework for managing and aligning multiple organisational improvement initiatives. Total Quality Management \& Business Excellence, v. 22, n. 11, p. 1213-1236, 2011.

MOTTA, G. S.; QUINTELLA, R. H.; MELO, D. R. A. Jogos de empresas como componente curricular: análise de sua aplicação por meio de planos de ensino. Revista Organizações \& Sociedade, v. 19, n. 62, p. 437-452, 2012.

NORRIS, D. External validity of business games. Developments in Business Simulation and Experiential Learning, v. 13, p. 126-129, 1986.

OAKSHOTT, L. Business modelling and simulation. Harlow: Pearson, 1997.

ROSAS, A. R.; SAUAIA, A. C. A. Jogos de empresas na Educação Superior no Brasil: perspectivas para 2010. In: ENCONTRO NACIONAL DA ASSOCIAÇÃO NACIONAL DOS PROGRAMAS DE PÓS-GRADUAÇÃO EM ADMINISTRAÇÃO, 30., 2006, Salvador. Anais... Salvador: Anpad, 2006.

SEMINÁRIOS EM ADMINISTRAÇÃO -SEMEAD. Anais dos Seminários em Adminsitração. [2017]. Disponível em: <http://semead.com. br/21/edicoes-anteriores/>. Acesso em: 28 out. 2017.

SIMPÓSIO DE ENGENHARIA DE PRODUÇÃO - SIMPEP. Edições anteriores. [2017]. Disponível em: <http://www.simpep.feb.unesp. br/index.php>. Acesso em: 28 out. 2017.

SIMULATION \& GAMING: AN INTERDISCIPLINARY JOURNAL. LOS Angeles, CA: Sage, 1970-2017. 
STAINTON, A. J.; JOHNSON, J. E.; BORODZICZ, E. P. Educational validity of business gaming simulation: a research methodology framework. Simulation \& Gaming: An Interdisciplinary Journal, v. 5, n. 41, p. 705-723, 2010.

VERSIANI, Â.; FACHIN, R. C. Avaliando aprendizagem em simulações empresariais. Cadernos EBAPE.BR, Rio de Janeiro, v. 5, n. esp., p. 1-13, 2007.
WOLFE, J.; KEYS, B. Business simulations, games and experiential learning in international education. New York: Haworth, 1997.

WOLFE, J. The effectiveness of business games in strategic management course work. Simulation \& Gaming: An Interdisciplinary Journal, v. 28, n. 4, p. 360-376, 1997.

Kaizô Iwakami Beltrão

ORCID: http://orcid.org/0000-0002-3590-8057

Doutor em Estatística pela Princeton University; Professor titular na FGV EBAPE, Rio de Janeiro - RJ, Brasil. E-mail: Kaizo.Beltrao@fgv.br 